\title{
Plasma Sintering of Unalloyed Iron: A Study of Surface Porosity
}

\author{
Jorge Magner Lourenço ${ }^{\mathrm{a}, \mathrm{b}}$, Ana Maria Maliska ${ }^{\mathrm{b}}$, Aloísio Nelmo Klein ${ }^{\mathrm{b}}$, \\ Joel Louis Rene Muzart ${ }^{\mathrm{b}}$ \\ ${ }^{a}$ Centro Federal de Educação Tecnológica, \\ CEFET-RN, GETIN, Natal - RN, Brazil \\ ${ }^{\mathrm{b}}$ LABMAT, Departamento de Engenharia Mecânica, \\ Universidade Federal de Santa Catarina, 88040-900 Florianópolis - SC, Brazil
}

Received: August 01, 2003; Revised: November 15, 2003

\begin{abstract}
Samples of unalloyed iron powder were compacted and sintered in an abnormal glow discharge, generated in a gas mixture of $80 \% \mathrm{Ar}+20 \% \mathrm{H}_{2}$ by using a pulsed power source. The samples were placed on a holder, acting as the discharge cathode, and were heated by the bombardment of ions, strongly accelerated in the cathode sheath. Sintering was performed at temperatures of 1173,1273 and $1373 \mathrm{~K}$ for $30 \mathrm{~min}$, varying the voltage applied to the cathode from 400 to $700 \mathrm{~V}$ and pressure ranging from 470 to $2650 \mathrm{~Pa}$. It is shown that the kinetic energy of ions striking the sample surface increased approximately three times, when the voltage changed from 400 to $700 \mathrm{~V}$, with a corresponding reduction of surface porosity. The surface sealing is related to the ion bombardment, which produced a high mobility of surface atoms and consequent enhanced diffusion as well as sputtering and condensation on the concave surface, resulting in an activation of surface sintering.
\end{abstract}

Keywords: Powder metallurgy, Plasma sintering, Surface porosity

\section{Introduction}

Glow discharge processes, as plasma assisted chemical vapor deposition (PACVD), plasma assisted physical vapor deposition (PAPVD), etching, nitriding or nitrocarburizing and surface cleaning are exhaustively used in industry ${ }^{1-12}$. In these techniques, the reactive species generated in the plasma produce an activated processing and the ion bombardment of the parts or the target is used for heating or sputtering respectively. Sintering of ceramics using microwave cavities, hollow cathode devices and microwave or RF-inductively coupled discharges have been investigated for plasma sintering ${ }^{13-16}$. The technique was applied to sinter ceramics as alumina or $\mathrm{MgO}$ and $\mathrm{MgO}-\mathrm{TiC}$. In those papers it has been reported that ceramics could be sintered to high density at high sintering rates. Heat transfer mechanism and the surface cleaning of the particles in the plasma environment are suggested to be responsible for the enhanced sintering. High-density samples at high rate sintering may also be obtained using the PAS (plasma activated sintering) or SPS (spark plasma sintering) process ${ }^{17-22}$. The pulsed voltage applied to the sample removes impurities from par- ticle surfaces and activates sintering. Following the cleaning of the particle surfaces, a direct current associated with a pulsed one flows among the powders and the contact resistance between the particles generates Joule heat ${ }^{23}$. This localized heating accelerates the formation of necks, leading to the activation of sintering. The application of plasma technology on powder metallurgy processing is mainly used for surface treatment ${ }^{24-27}$, cleaning ${ }^{28}$ or sintering ${ }^{29-33}$. In these papers, an abnormal glow discharge of a gas mixture constituted of argon, hydrogen, nitrogen and methane was used. The abnormal glow discharge is characterized by the whole covering of the cathode by the glow region ${ }^{2}$, supplying a uniform treatment. A negatively biased voltage was applied to the cathode, generating an electric field in the cathode sheath, where ions are strongly accelerated. Collisions between ions and atoms or molecules of the gas discharge in the cathode sheath resulted in a flow of fast neutrals toward the cathode ${ }^{2}$. When the sample is placed on the cathode, the heating is provided by direct bombardment of ions and fast neutrals.

*e-mail: ana@materiais.ufsc.br 
In this paper, a D.C. discharge, generated in an argon/ hydrogen gas mixture, was used to sinter unalloyed iron, with the sample placed on a holder, which worked as the cathode. In order to study the influence of ion bombardment on the surface porosity, the negative voltage connected to the cathode was varied.

\section{Experimental and Materials}

The plasma sintering apparatus is shown in Fig. 1. The reactor consisted of a steel cylinder $300 \mathrm{~mm}$ in diameter and $300 \mathrm{~mm}$ in height, sealed by O-rings and closed in both ends by steel plates. Connections for gas inlet, vacuum pump, pressure sensor and electrodes, electrically insulated, were connected to the steel plates. Prior to sintering, the system was pumped down by a two-stage mechanical pump until a residual pressure of less than $1.3 \mathrm{~Pa}$ was reached. The gas mixture consisting of $80 \%$ argon (99.999\% pure) and $20 \%$ hydrogen ( $99.998 \%$ pure) was adjusted using two Datametrics mass flow controllers whose full-scale value was $8.3 \times 10^{-6} \mathrm{~m}^{3} / \mathrm{s}^{-1}(500 \mathrm{sccm})$ and the total gas flow was set to $4 \times 10^{-6} \mathrm{~m}^{3} / \mathrm{s}^{-1}(240 \mathrm{sccm})$. The pressure in the vacuum chamber was adjusted and measured with accuracy better than $2 \%$ by a manual valve and measured using an Edward capacitance manometer of $13300 \mathrm{~Pa}$ (100 Torr) full-scale.

Iron powder DC177 from Hoeganaes was sieved in order to obtain particle size ranging from 43 to $63 \mu \mathrm{m}$. Then the powder was mixed with $0.6 \% \mathrm{wt}$ of zinc stearate and compacted to a pressure of $500 \mathrm{MPa}$ using a double action press with moving die body. The samples, $9.5 \mathrm{~mm}$ in diameter and $6 \mathrm{~mm}$ high, were placed on a steel AISI 1020 support working as the cathode of the discharge. The experimental scheme is illustrated in Fig. 2. The cathode was negatively biased, using a power source of $5 \mathrm{~kW}$, which generated a square waveform pulse voltage varying from 400 to $700 \mathrm{~V}$. The sample temperature was adjusted by varying the time switched on $\left(\mathrm{t}_{\text {on }}\right)$ of the pulse, which could be varied from 10 to $240 \mu \mathrm{s}$ and the total on/off time was $250 \mu \mathrm{s}$. Symmetrically placed to the sample, a cylinder of sintered

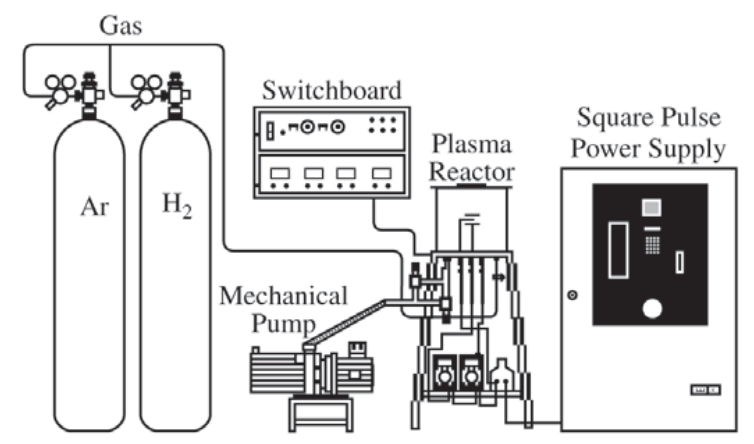

Figure 1. Experimental apparatus. iron $9.5 \mathrm{~mm}$ in diameter and $6 \mathrm{~mm}$ height was used for temperature measurements. The type $\mathrm{K}$ thermocouple was protected with a stainless steel cover, $1.5 \mathrm{~mm}$ in diameter, electrically insulated with $\mathrm{Al}_{2} \mathrm{O}_{3}$ and inserted $5 \mathrm{~mm}$ into the reference sample. Dewaxing was performed in a conventional furnace at a temperature of $773 \mathrm{~K}$ for $30 \mathrm{~min}$ in hydrogen atmosphere. Plasma sintering was carried out for $30 \mathrm{~min}$, at temperatures of 1173,1273 and $1373 \mathrm{~K}$, using pulse voltage of $400,500,600$ and $700 \mathrm{~V}$, maintaining $\mathrm{t}_{\text {on }}$ at 80,110 and $140 \mu \mathrm{s}$. At each conditions of voltage and $\mathrm{t}_{\text {on }}$, the temperature was adjusted by varying the gas pressure typically from 370 to $2650 \mathrm{~Pa}$. For comparison, a set of samples was sintered in a conventional furnace in hydrogen gas at atmospheric pressure, following the same processing cycle.

Micrographs of the surface of the sintered samples were obtained by using a scanning electron microscope. The BSE (back-scattered electron) pictures for the image analyses were taken using a $200 \times$ magnification. The porosity was determined by image analyses using a rectangle of $480 \times 360 \mathrm{~mm}$ of the binarised image. The results are an average of measurements carried out in six different positions on the lateral part of the sample.

\section{Results and Discussion}

\subsection{Comparative results of conventional and plasma sintering}

Micrographs of the lateral surface of green (a) and sintered at $1373 \mathrm{~K}$ (b) samples are presented in Figs. 3, 4 and 5. The images were carried out at the same region in order to identify the evolution of the sealing after sintering. The plasma sintering was performed in two conditions, whose parameters are presented in Table 1.

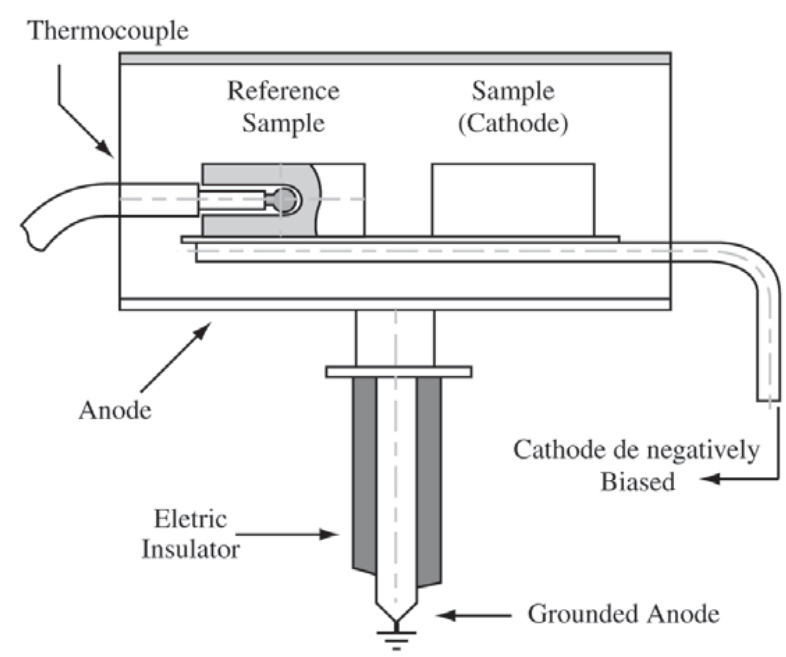

Figure 2. Schematic representation of the electrodes geometry. The sample was placed on the cathode of the glow discharge. 


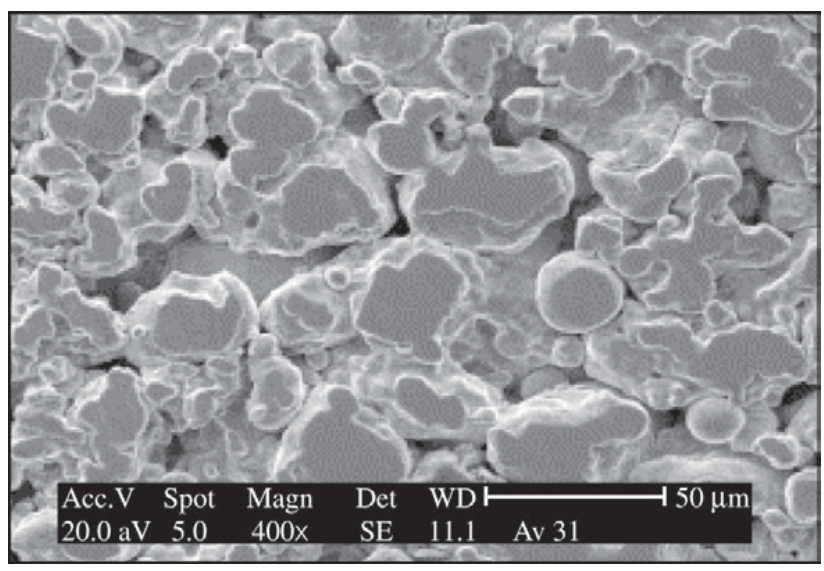

(a)

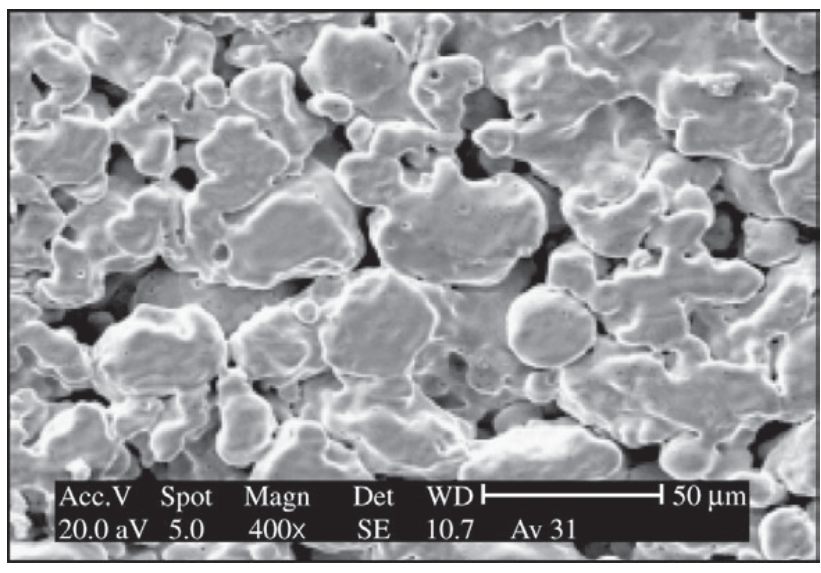

(b)

Figure 3. a) Micrographs of samples surface in the green state; b) sintered in a conventional furnace.

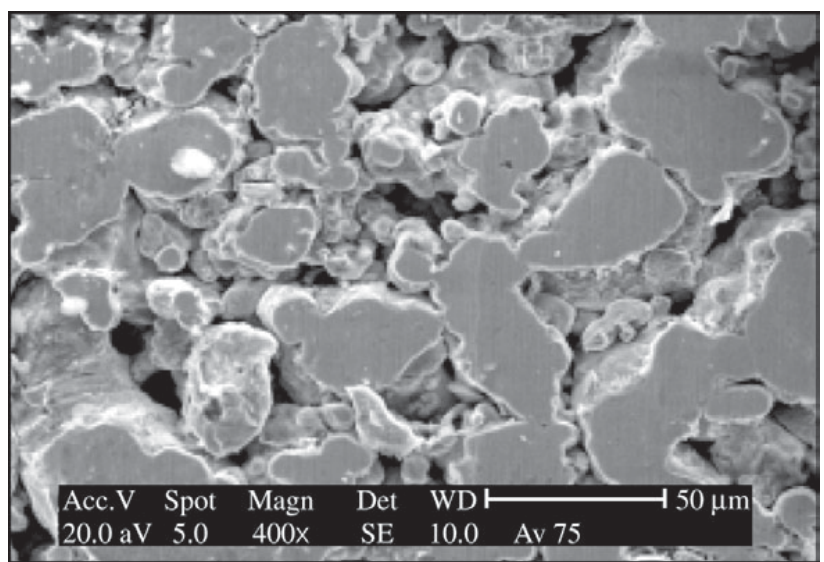

(a)

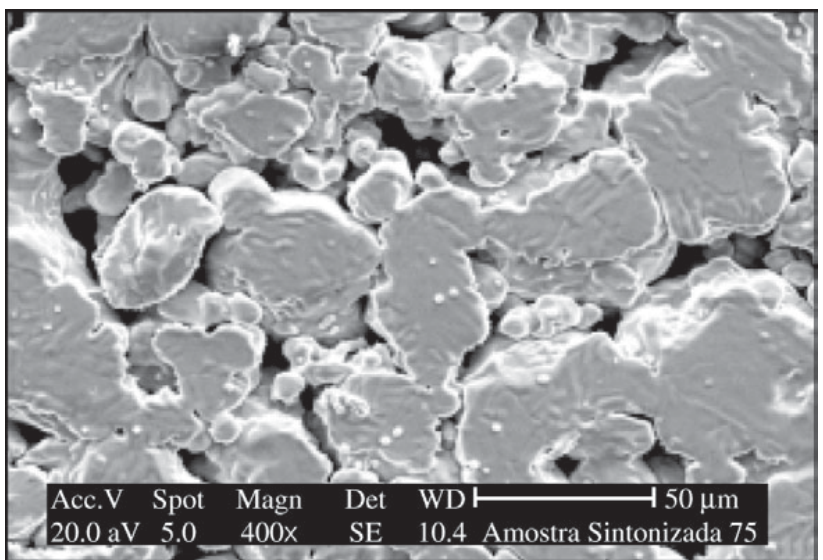

(b)

Figure 4. a) Micrographs of samples surface in the green state; b) plasma-sintered in condition $1\left(400 \mathrm{~V}, \mathrm{t}_{\text {on }}=80 \mu \mathrm{s}\right.$ and $\left.2650 \mathrm{~Pa}\right)$.

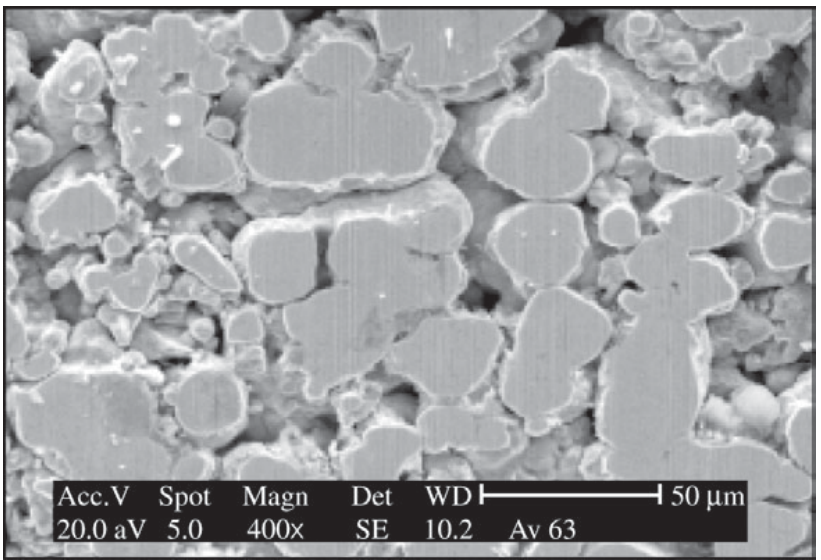

(a)

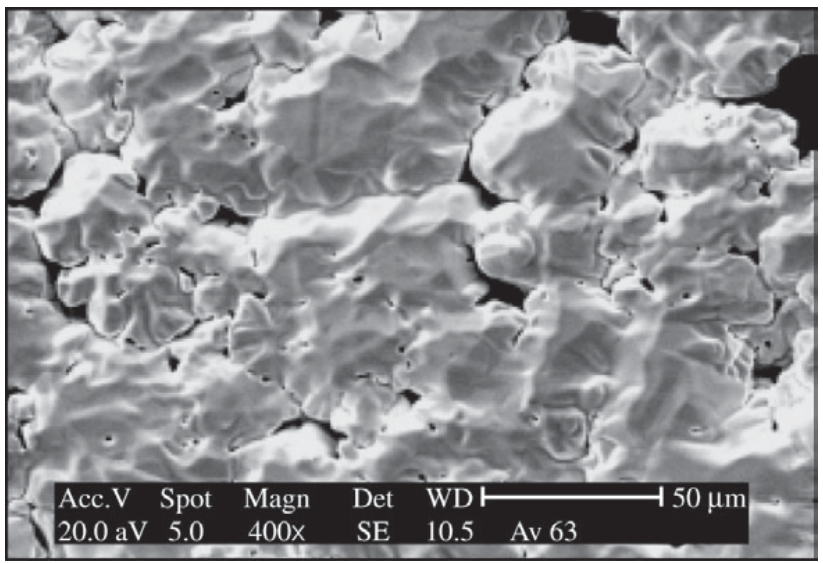

(b)

Figure 5. a) Micrographs of samples surface in the green state; b) plasma-sintered in condition $2\left(700 \mathrm{~V}, \mathrm{t}_{\text {on }}=140 \mu \mathrm{s}\right.$ and $\left.470 \mathrm{~Pa}\right)$. 
The images of sample surfaces, sintered in a conventional furnace and by using plasma technique in condition 1, are presented in Fig. 3 and 4. In both cases, the surface aspect after sintering in furnace and in plasma $(400 \mathrm{~V}$ and pressure of $2650 \mathrm{~Pa}$ ), is similar. The formation of necks was observed, with no significant sealing of the pores on the surface, particularly the larger ones. Such an effect is in good agreement with what is generally accepted i.e. that surface diffusion cannot cause pore shrinkage, as discussed by Thümmler and Oberacker ${ }^{34}$. However, for the sample plasma-sintered in condition 2, a significant porosity sealing was observed, which is attributed to higher energy of ion bombardment of the sample surface, as compared to the condition 1. Such an effect is associated with the enhanced condensation of atoms resulting from sputtering and the increased surface diffusion of atoms resulting from the highenergy ion bombardment of the sample surface. As discussed by Thümmler and Oberacker ${ }^{34}$, besides the volume and grain boundary diffusion, there are two mechanisms of material transport during sintering: evaporation and condensation of atoms and surface diffusion. The condensation of atoms occurs preferentially on the concave surface, the pore, where vapour pressure is lower. For the same reason, surface diffusion takes place from the convex to the concave surface, where the particle contact initiates. Then, by diffusion of theses atoms, the particle contacts grow. On the surface of the sample, sintering may result mainly from the condensation and surface diffusion of atoms. By using plasma technique, ions arriving at the interface between the glow region and the cathode sheath are strongly accelerated towards the cathode. At usual sintering pressures (between 300 and $4000 \mathrm{~Pa}$ ) the flow of ions of high energy, typically 10 to $60 \mathrm{eV}^{35}$, impacting the cathode causes three main effects: heating, sputtering of atoms from the cathode and kinetic energy transfer to the atoms of the surface. When the pressure was maintained at $470 \mathrm{~Pa}$, the mean free path of ions, between collisions with atoms, is higher than that occurring when the pressure was fixed at $2650 \mathrm{~Pa}$. Thus, it could be expected that the kinetic energy of ions striking the sample surface, which is an increasing function of the electric field in the cathode sheath and inversely proportional to the gas pressure, is significantly higher in condition 2 as compared to condition 1. As a consequence of sputtering, a high concentration of iron atoms occurred in the gas phase accompanied by an enhanced condensation. In addition, the higher energy of ions striking the sample surface resulted in an activated diffusion, contributing to the porosity sealing. In order to quantify the activated surface sintering observed by using condition 2 , results of surface porosity, measured for three sintering temperatures, are presented in Fig. 6. As expected, in all sintering conditions, as the temperature increased, there was an approximately linear reduction of the surface porosity. For conven-
Table 1. Plasma parameters

\begin{tabular}{lccc}
\hline Condition & Voltage $(\mathrm{V})$ & $\mathrm{t}_{\text {on }}(\mu \mathrm{s})$ & Pressure $(\mathrm{Pa})$ \\
\hline 1 & 400 & 80 & 2650 \\
2 & 700 & 140 & 470 \\
\hline
\end{tabular}

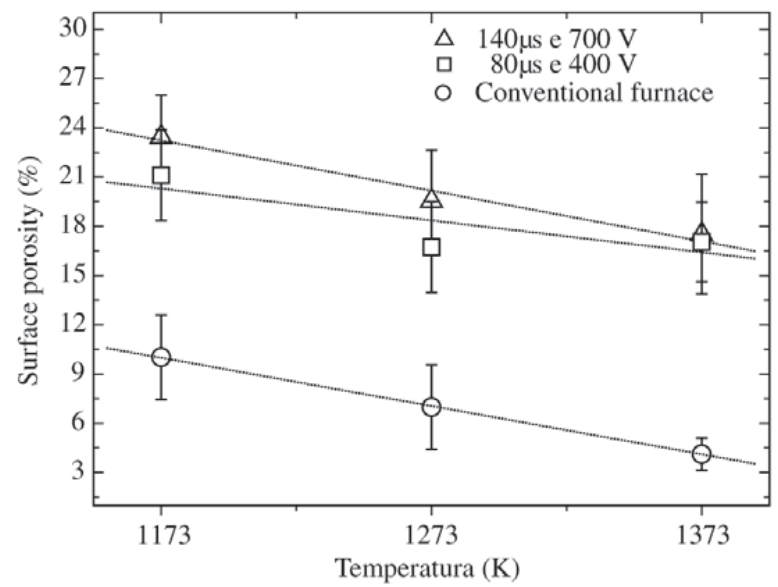

Figure 6. Variation of surface porosity as a function of temperature of samples sintered in a conventional furnace and by plasma technique in conditions 1 and 2 .

tional furnace and plasma sintering in condition 1, considering the dispersion of the measurements, the same porosity was obtained, ranging from approximately $23 \%$ at $1173 \mathrm{~K}$ to $17 \%$ at $1373 \mathrm{~K}$. On the other hand, when sintering was performed by plasma in condition 2 , the porosity ranged from 10 to $4 \%$ for the same temperature variation.

\subsection{Variation of surface porosity as a function of average energy of ion bombardment}

The average kinetic energy of ions striking the sample surface was varied by changing the voltage applied to the cathode. The experiments were performed for a $t_{\text {on }}$ fixed at 80 and $140 \mu \mathrm{s}$ and the temperature was maintained at $1373 \mathrm{~K}$. The current of the discharge and consequently the temperature is an increasing function of the voltage applied to the cathode as well as of the gas pressure. Thus, as $\mathrm{t}_{\text {on }}$ was maintained constant, in order to maintain the temperature at $1373 \mathrm{~K}$, by increasing the voltage applied to the cathode, the pressure of the discharge had to be lowered as shown in Table 2.

The energy of ions (E) is proportional to the voltage fall (V) in the cathode sheath, which is nearly the voltage applied to the cathode ${ }^{36}$ and an inverse function of the number of collisions $(\mathrm{N})$ :

$$
E=C_{1}\left(\frac{V}{N}\right)
$$


The number of collisions of ions with atoms or molecules is proportional to the thickness $d$ of the cathode sheath and inversely proportional to the mean free path of the ions. On the other hand, the mean free path is inversely proportional to the number of atoms or molecules in the gas phase, which is itself proportional to the pressure, at constant temperature. Then,

$$
N=C_{2}(p \cdot d)
$$

It follows that,

$$
E=C_{3}\left(\frac{V}{p \cdot d}\right)
$$

where $C_{1}, C_{2}$ and $C_{3}$ are constant values.

Results published by Guntherschulze in 1930 and presented by von Engel ${ }^{37}$, show the variation of $p . d$ as a function of the voltage applied to the discharge for argon and hydrogen gases. Considering the gas mixture of $80 \% \mathrm{Ar}+20 \% \mathrm{H}_{2}$, the values of $p . d$ were calculated and are represented in Fig. 7 by squares. The experimental values of the pressure for different voltages, for a $t_{\text {on }}=140 \mu \mathrm{s}$, used to sinter the samples at $1373 \mathrm{~K}$ are also plotted at Fig. 7 and identified by crosses. The product p.d corresponding to each sintering pressure was then determined, and by using equation (3) the factor $\mathrm{V}(p . d)^{-1}$ proportional to the energy of ions, was calculated. The same procedure was used, considering a curve similar to that presented in Fig. 7, to calculate the factor V. $(p . d)^{-1}$ for $\mathrm{t}_{\mathrm{on}}=80 \mu \mathrm{s}$. The results are presented in Table 3. Clearly, the energy of ions bombarding the surface of the sample increased as a function of the increasing voltage, being around 3 times higher at 700 than at $400 \mathrm{~V}$. Considering that the average ion energy is, typically, lower than $100 \mathrm{eV}^{35}$, the ion implantation is negligi$\mathrm{ble}^{2}$; thus, interaction occurs mainly with the surface atoms. As a consequence, the increase of energy of the ions bombarding the sample surface resulted in an increase of kinetic energy that was transferred to the atoms on the surface. Such an effect, takes place not only to evaporated or sputtered atoms followed by the deposition, but also to atoms of the surface lattice. Therefore, an enhanced mobility and surface diffusion of the iron atoms occurred, resulting in an efficient porosity sealing, as it shown in Fig. 8.

\footnotetext{
3.3. Variation of surface porosity as a function of $t_{\text {on }}$ of the pulse of the power source
}

Results of surface porosity of samples sintered at $1373 \mathrm{~K}$ as a function of $\mathrm{t}_{\text {on }}$, are presented in Fig. 9. The sintering experiments were performed for the power source voltage fixed at 400 and $700 \mathrm{~V}$. In order to maintain the temperature at $1373 \mathrm{~K}$, the pressure was adjusted as shown in Table 4. The energy of ions striking the sample surface in each condition was calculated using the same procedure used previously and the results are also presented in Table 4. From the variation of $p . d$ as a function of voltage, presented in Fig. 7, the evaluation of the number propor-

Table 2. Gas pressure of the glow discharge for different voltage applied to the cathode, for $\mathrm{t}_{\text {on }}$ fixed at 80 and $140 \mu$ s. The sample temperature was maintained at $1373 \mathrm{~K}$.

\begin{tabular}{ccc}
\hline $\mathrm{t}_{\text {on }}(\mu \mathrm{s})$ & Voltage $(\mathrm{V})$ & Pressure $(\mathrm{Pa})$ \\
\hline \multirow{3}{*}{80} & 400 & 2650 \\
& 500 & 1300 \\
& 600 & 780 \\
& 700 & 580 \\
140 & 400 & 1185 \\
& 500 & 825 \\
& 600 & 630 \\
& 700 & 470 \\
\hline
\end{tabular}

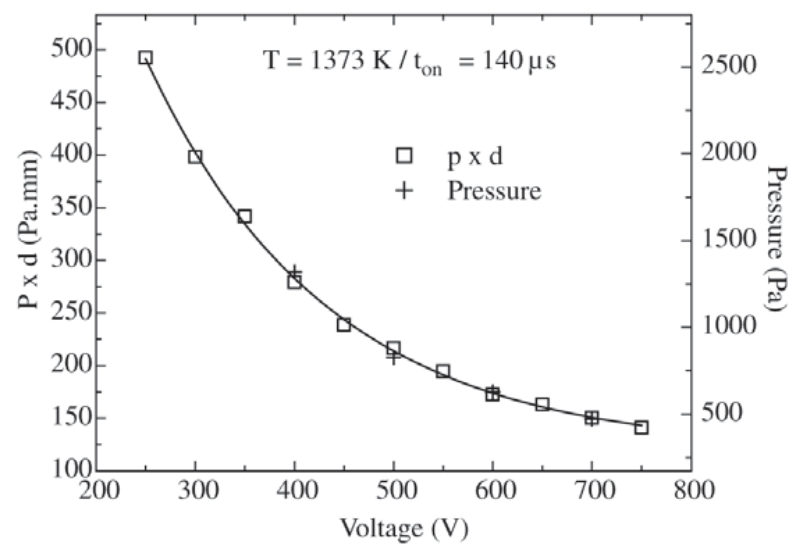

Figure 7. Variation of the product $p d$ as a function of the voltage applied to the discharge and of the pressure necessary to maintain the sintering temperature at $1373 \mathrm{~K}$ for different voltages with $\mathrm{t}_{\text {on }}$ fixed at $140 \mu \mathrm{s}$.

Table 3. Variation of the product p.d and $\mathrm{V}(p . d)^{-1}$ as a function of voltage. The sample temperature was maintained at $1373 \mathrm{~K}$.

\begin{tabular}{lccc}
\hline $\mathrm{t}_{\text {on }}(\mu \mathrm{s})$ & Voltage $(\mathrm{V})$ & $p . d($ Pa.mm $)$ & $\mathrm{V} /(p . d)(\mathrm{V} / \mathrm{Pa} . \mathrm{mm})$ \\
\hline \multirow{3}{*}{80} & 400 & 290 & 1.38 \\
& 500 & 210 & 2.37 \\
& 600 & 170 & 3.60 \\
& 700 & 160 & 4.38 \\
140 & 400 & 270 & 1.48 \\
& 500 & 210 & 2.43 \\
& 600 & 170 & 3.48 \\
& 700 & 150 & 4.67 \\
\hline
\end{tabular}




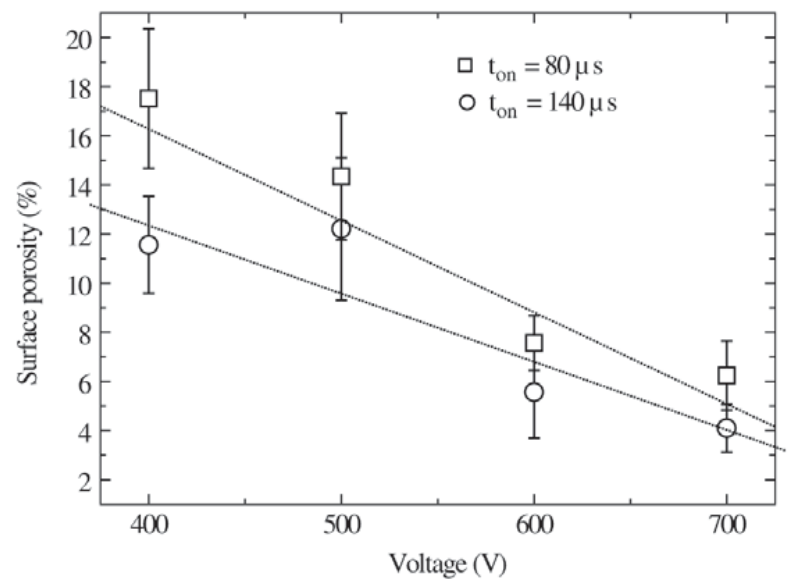

Figure 8. Variation of surface porosity of samples sintered at 1373 $\mathrm{K}$ as a function of the discharge voltage.

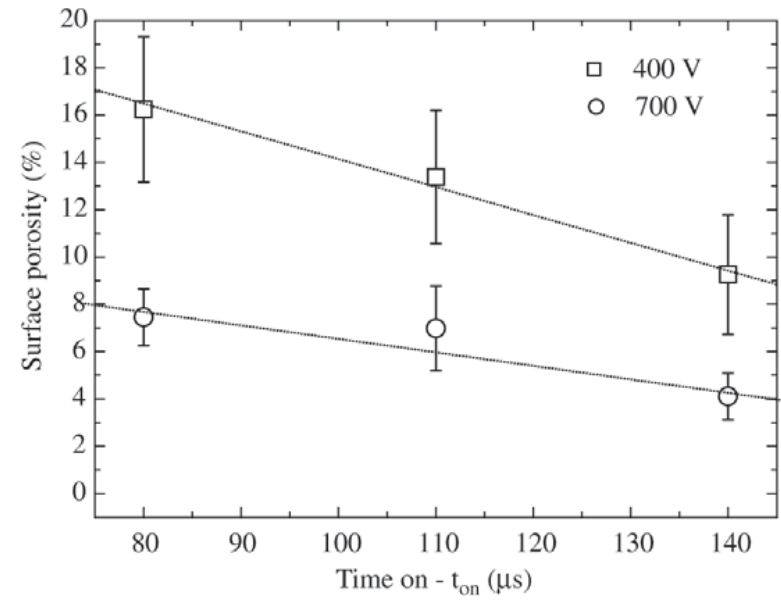

Figure 9. Variation of surface porosity of sintered samples as a function of $\mathrm{t}_{\text {on }}$.

Table 4. Variation of pressure, product $p \cdot d$ and $\mathrm{V}(p \cdot d)^{-1}$ as a function of $\mathrm{t}_{\text {on }}$ for the voltage of 400 and $700 \mathrm{~V}$ applied to the cathode. The sample temperature was maintained at $1373 \mathrm{k}$.

\begin{tabular}{lcccc}
\hline Voltage $(\mathrm{V})$ & $\mathrm{t}_{\text {on }}(\mu \mathrm{s})$ & Pressure $(\mathrm{Pa})$ & $p . d(\mathrm{~Pa} . \mathrm{mm})$ & $\mathrm{V} /(p . d)(\mathrm{V} / \mathrm{Pa} . \mathrm{mm})$ \\
\hline \multirow{4}{*}{400} & 80 & 2640 & 290 & 1.38 \\
& 110 & 1610 & 280 & 1.43 \\
& 140 & 1185 & 270 & 1.48 \\
700 & 80 & 580 & 160 & 4.38 \\
\hline & 110 & 510 & 160 & 4.38 \\
\hline
\end{tabular}

tional to ion kinetic energy was calculated with an accuracy of $10 \%$. Thus, it can be considered that in all experiments performed at a fixed voltage, the energy of ions impinging the sample surface was the same. As expected, the porosity measured for a voltage of $700 \mathrm{~V}$ was significantly lower than the one obtained at $400 \mathrm{~V}$, as a consequence of the higher kinetic energy of ions. On the other hand, the decrease of surface porosity measured, either at voltages of 400 and $700 \mathrm{~V}$, for an increasing function of $\mathrm{t}_{\text {on }}$, is simply attributed to the higher effective time of ion bombardment of the sample surface. Such a result is related to the higher time of activated surface sintering mechanisms, which is an additional evidence of the influence of ion bombardment on the surface porosity sealing.

\section{Conclusions}

An abnormal glow discharge has been shown to be an efficient approach to sinter metallic components. When the sample was placed on a holder, which worked as the cathode of the discharge, the surface porosity was strongly dependent on the kinetic energy of the ions striking the sam- ple. The higher the kinetic energy of ions bombarding the sample surface, the lower was the measured surface porosity. In addition, increasing the effective time of ion bombardment of the sample surface, a reduction of porosity was observed, confirming the dependence between surface porosity and interaction ion-surface. Such an effect is attributed to surface sintering mechanisms, as enhanced condensation of atoms resulting from sputtering and the activated surface diffusion of iron atoms resulting from the ion bombardment of the sample surface.

\section{Acknowledgments}

This work was performed using funds from FINEP/MCT (PRONEX) and CNPq (PADCT) research grant.

\section{References}

1. Rhode, S.L.; Münz, W.D. Advanced Surface Coatings: A Handbook of Surface Engineering, Blake \& Son Ltd, p. 127, 1991.

2. Chapman, B. Glow Discharge Processes: Sputtering and Plasma Etching, First Edition, John Wiley \& Sons, New 
York, p. 178, 1980.

3. Butz-Jorgensen, C.V.; Kringhoj, P.; Nielsen, J.F.; Bottiger, J. Surf. Coat. Technol., v. 135, p. 299, 2001.

4. Window, B. Surf. Coat. Technol., v. 81, p. 92, 1996.

5. Fontana, L.C.; Muzart, J.L.R. Surf. Coat. Technol., v. 114, p. 7, 1999.

6. Hombecck, F., Bell, T., Surface Engineering, v. 7, n. 1, p. 45, 1991.

7. Rembges, W., Metal Powder Report, p. 765, 1988.

8. Bell, T.; Sun, Y.; Suhadi, A. Vacuum, v. 59, p. 14, 2000.

9. Musil, J.; Vlèek, J.; Rù•ièka, M. Vacuum, v. 59, p. 940, 2000.

10. Belkind, A.; Li, H.; Clow, H.; Jansen, F. Surf. Coat. Technol., v. 76-77, p. 738, 1995.

11. Petasch, W.; Kegel, B.; Schmid, H.; Lendenmann, K; Keller, H.U. Surf. Coat. Technol., v. 97, p. 176, 1997.

12. Mozetiè, M. Vacuum, v. 61, p. 367, 2001.

13. Johnson, D.L.; Sanderson, W.B.; Knowlton, J.M.; Kemer, E.L.; Chen, M.Y. Science of Sintering, v. 20, n. 2/3, p. 109, 1988.

14. Page, R.A.; Spooner, S.; Sanderson, W.B.; Johnson, D.L. J. Am. Ceram. Soc., v. 71, n. 12, p. 1125, 1988.

15. Bengisu, M.; Inal, O.T. J. Mater. Sci., v. 29, p. 5475, 1994.

16. Su, H.; Johnson, D.L. J. Am. Ceram. Soc., v. 79, n. 12, p. 3199, 1996.

17. Groza, J.R.; Risbud, S.H.; Yamazaki, K. J. Mater. Res., v. 7, n. 10, p. 2643, 1992.

18. Mishra, R.S.; Schneider, J.A.; Shackelford, J.F.; Mukherjee, A. K. NanoStructured Materials, v. 5, n. 5, p. 525, 1995.

19. Li, W.; Gao, L. J. Euro. Ceramic Soc., v. 20, p. 2441, 2000.

20. Ye, L.L.; Liu, Z.G.; Raviprasad, K.; Quan, M.X.; Umemoto, M.; Hu, Z.K. Materials Science and Engineering, v. A241, p. 290, 1998.

21. Takeuchi, T.; Bétourné, E.; Tabuchi, M.; Kageyama, H.; Kobayashi, Y.; Coats, A.; Morrison, F.; Sinclair, D.C.;
West, A.R. J. Mater. Sci., v. 34, p. 917, 1999.

22. Murakami, T.; Komatsu, M.; Kitahara, A.; Kawahara, M.; Takahashi, Y.; Ono, Y. Intermetallics, v. 7, p. 731, 1999.

23. Matsumoto, A.; Katoh, K.; Andoh, K. Corrosion Engineering, v. 44, p. 751, 1995.

24. Tosic, M.M.; Tersic, I.; Gligorijevic, R. Vacuum, v. 40, n. 1, p. 131, 1990.

25. Bocchini, G.F. Int. J. Powder Metall., v. 22, n. 3, p. 185, 1986.

26. Maliska, A.M.; Klein, A.N.; Souza, A.R. Surf. Coat. Technol., v. 70, p. 175, 1995.

27. Maliska, A.M.; Oliveira, A.M.; Klein, A.N.; Muzart, J.L.R. Surf. Coat. Technol., v. 141, p. 128, 2001.

28. Santos, M.A.; Silva, H.R.T.; Muzart, J.L.R.; Maliska, A.M. Third Inter. Latin American Conf. on Powder Technol, Florianópolis, p. 561, Nov., 26-28, 2001.

29. Muzart, J.L.R.; Batista, V.J.; Franco, C.V.; Klein, A.N. Advances in Powder Metallurgy \& Particulate Materials, v. 3, p. 77, 1997.

30. Batista, V.J.; Binder, R.; Klein, A.N.; Muzart, J.L.R. Int. J. Powder Metall, v. 34, n. 8,p. 55, 1998.

31. Batista, V.J.; Mafra, M.; Muzart, J.L.R.; Klein, A.N.; Back, N. Mater. Sci. Forum, v. 299, n. 3, p. 249, 1999.

32. Brunatto, S.F.; Kühn, I.; Klein, A.N.; Muzart, J.L.R. Third Inter. Latin American Conf. on Powder Technol, Florianópolis, p. 488, Nov., 26-28, 2001.

33. Brunatto, S.F.; Kühn, I.; Klein, A.N.; Muzart, J.L.R. Mat. Sci. Eng. A, v. 343, n. 1-2, p. 163, 2002.

34. Thümmler, F.; Oberacker, R. Introduction to Powder Metallurgy, The Institute of Materials, London, p. 184, 1993.

35. Mason, R.S.; Pichilingi, M. J. Phys. D: Appl. Phys, v. 27, p. 2363, 1994.

36. Butz-Jørgensen, C.V.; Bøttiger, J.; Kringhøj, P. Surf. Coat. Technol., v. 137, p. 104, 2001.

37. Von Engel, A. Ionized Gases, AIP Press, Woodbury, N.Y., p. 228, 1994. 
